\title{
Second OR Temperature
}

National Cancer Institute

\section{Source}

National Cancer Institute. Second OR Temperature. NCI Thesaurus. Code C159283.

The second body temperature recorded in the operating room for the participant. 